\title{
A NOÇÃO DE BELEZA NA SOCIEDADE DOS LIKES: IMAGINAÇÃO, FANTASIA E CONSUMO NAS REDES SOCIAIS DIGITAIS
}

Resenha de: HAN, Byung-Chul. A salvação do belo. Petrópolis/RJ: Vozes, 2019, I26p.

Julio Marinho Ferreira'

O filósofo e ensaísta sul-coreano, radicado na Alemanha, Byung-Chul Han, país onde leciona filosofia e estudos culturais, é um importante teórico das transformações de nossa sociedade altamente tecnológica, com análises que versam sobre as formas de poder empregadas nas relações sociais através do capitalismo neoliberal - a psicopolítica, as transformações dessa mesma sociedade informatizada, tendo como base os escritos de teóricos como Michel Foucault (disciplina e biopoder) e Gilles Deleuze (sociedade de controle e virtual), entre outros. Sendo um profundo conhecedor da filosofia existencialista (por ter feito seus estudos de formação na Alemanha, berço dessa vertente), Han procura entender o indivíduo na contemporaneidade a partir de referenciais que discutam a dimensão do Ser e do existir e os seus impactos no Eu, e como a alta tecnologia informacional, massificada atualmente, tenderia (ou não) a afetar as interações humanas.

Os usos do privado em contextos de exposição e de consumo exagerado, ambiente nos quais as redes sociais virtuais se tornaram um marcante retrato do contemporâneo, é um dos tópicos atualmente trabalhados pelo filosofo sul-coreano. Nesse sentido, Han tece uma original análise acerca dos usos da beleza, articulando elementos de filosofia, de estética, de política, da pornografia, entre outros, já que todos esses aspectos são marcantes nas relações humanas e sociais, além de servir de guia ao principal de sua discussão: o belo. Tema recente, principalmente, nos contextos interativos do virtual e do digital. Assim, ao tratar de uma "salvação do belo", como o título de seu ensaio aponta, Han nos olha e pergunta o que seria esse belo e, como salvá-lo?

\footnotetext{
1 Doutorando em Sociologia pela UFPel, bolsista Capes/CNPq. Email: juliomarferre@hotmail.com
} 
A noção de beleza na sociedade dos likes. imaginação, fantasia e consumo nas redes sociais digitais | Julio Marinho Ferreira

Imaginar o belo, como algo a ser salvo, é se ater aos detalhes que fazem com que alguma coisa seja buscada como fonte de beleza, e como fuga (do abjeto e do feio). Com isso em mente, Han inicia seu ensaio tratando de um aspecto marcante nessa busca: o corpo liso e o seu alcance estético. Esse liso é "a marca do presente, é ele que conecta as esculturas de Jeff Koons, iPhones e a depilação à brasileira" (HAN, 2019, p. 07). Koons, artista e escultor norteamericano, tem na famosa obra Rabbit, a peça de arte mais cara a ser vendida por um artista vivo (US \$ 91.1 milhões), um exemplo dos aspectos múltiplos do que seria beleza na sociedade atual. Na mencionada obra, um coelho gigante feito de aço inoxidável, o liso se mostra como um espelho a refletir o si mesmo e o redor, promovendo alegria e comunicação através de suas superficies brilhantes e coloridas - aspectos que todos parecem buscar no consumo. A analogia que Han faz com o coelho milionário de Koons é aquela que mostra um corpo liso (espelhado), um liso estético e refletivo como uma forma de abraçar o espectador (p. 09), o tornando motivado e tocado pelos reflexos, já que no liso não haveria o oculto nem o feio e sim uma (su)gestão de autoestima, uma busca pela autoimagem.

Saindo do liso artístico e refletivo de Koons, Han destaca o papel, legado atualmente aos aparelhos smartphones e seus lisos tácteis, ou seja, convidativos aos toques constantes, à uma sensibilidade do real, ao mesmo tempo que tende a esmorecer essa mesma noção da beleza (artificial e lisa). "A visibilidade exaustiva do objeto também arruína o olhar" (p. 16), ou seja, em Han, o consumo de imagem, dentro do belo liso e altamente tecnológico se mostra problemática. Esse mesmo belo virtual/digital seria higiênico por não trazer um cheiro (abjeção), como a mencionada, por Han, depilação à brasileira, o imperativo do liso belo e asséptico, onde os pelos são extirpados dando lugar ao mais puro liso táctil. Voltando ao liso dos smartphones, táctil ou informacional (redes sociais digitais) tem-se presenças e fugas, que indicam caminhos para um belo digital, padronizado, uma forma de exigências presente nos likes, a possibilidade de se curtir os lisos irreais, quase eróticos. 
A noção de beleza na sociedade dos likes. imaginação, fantasia e consumo nas redes sociais digitais | Julio Marinho Ferreira

Nesse sentido, "O corpo encontra-se hoje em crise. Não está despedaçado apenas em partes pornográficas, mas também em registros de dados” (p. 25).

A estética do liso é "uma superfície otimizada sem negatividade, provoca uma sensação completamente sem dor e resistência" (p. 29), que possibilitariam um deslizamento de sensações. Essas estéticas, para Han, podem ser representadas pelo velamento, pelo ferimento ou pelo desastre, sendo assim, pontos centrais para o entendimento da problemática da beleza como potência e busca, já que podem provocar sensações variantes e negativas. Como Han aponta, esse belo é oculto e precisa estar sempre encoberto para se fazer sentido (p. 43), se for revelado perderia sua graça. Esse encobrimento seria como um ferimento, um contato distanciado, podendo se pensar no ato ou na dor da perda como aspectos que deveriam ser extirpados, por tornarem o belo feio. A dor afastaria o amor (a beleza por si), já que "qualquer uso maior de algo que gerasse um ferimento é evitado" (p. 51). Voltando ao mundo informatizado do on-line, que Han evoca em vários pontos de seu ensaio, nas redes sociais o like como busca é uma forma de capturar o outro de uma maneira ambivalente, ao que Han aponta "não se pode ver o outro sem se expor a um ferimento" (p. 52). E o que (ou quem) seria esse outro?

Um outro é o consumidor voraz de imagens, que não consegue fechar os olhos (p. 57), o que poderia levar a uma estetização do desastre (do latim, des-astrum, sem estrelas), o que gera um constante risco. Dessa forma, de Kant e de Hegel, Han extrai apontamentos para o que seria esse desastre e seus riscos. No primeiro, não há um conhecimento de uma natureza desastrosa, e no segundo, o desastre pode ser afastado com a arte, e sua ação sobre o espírito humano, ou seja, a racionalidade. A beleza tanto pode ser um desastre quanto um acontecimento, uma aparência frágil e em constante risco.

A busca por um ideal de beleza aponta a questão de ser belo como ser verdadeiro, "sua percepção estética não é consumidora, mas contemplativa" (p. 69), na atualidade há muitos estímulos para o belo, e para os seus consumos, promovendo ações que acabam distanciando uma real estética da beleza em função de uma natureza social fraturada. Para essa fratura, ou 
A noção de beleza na sociedade dos likes. imaginação, fantasia e consumo nas redes sociais digitais | Julio Marinho Ferreira

ruptura, "uma figura é bela quando ela a corresponde, feia, em contrapartida, quando dela se aparta” (p. 70), já que o belo é algo, apenas, relacionado ao humano, a sua capacidade de perceber o que é velado. A política do belo, e sua racionalidade, pode retirar desse belo seu caráter consumista e vazio, transformando a solidez da busca em algo a ser superado. $\mathrm{Na}$ era das comunicações complexas, e descentralizadas, como a Internet e as redes sociais, o digital é tornado ordem, e retira o caráter do homem e de suas relações. Tudo parece ser vazio, o belo já não é mais o belo clássico, é apenas o liso, sem caráter (p. 75).

A beleza, então, é evocada como uma verdade, já que o vazio das interações via redes sociais precisa de caracteres legitimadores, indo além do simples liso, para adentrar a realidade. Evocando novamente Hegel, Han percebe que o objeto (objekt) é um oposto pelo qual o sujeito ganha uma relação livre (p. 79). As ações éticas das redes sociais, onde a circulação da imagem, e a busca da beleza, se fundem de maneira problemática, apontam para o desaparecimento da separação entre sujeito e objeto, entre o eu e o que me opõe (p. 81), dessa relação, pode-se notar que a verdade buscada acaba se opondo a ideia de massa, sendo que as redes sociais são os ambientes dessas massas. Massa é o sem-forma, enquanto beleza é a forma (págs. 82-83), e Han esclarece, "da massa de dados, como o big data, pode-se destilar informações que podem até ser uteis, mas que não geram nem conhecimento nem verdade (p. 83).

O belo é o produto central de uma lógica de consumo como a expressa no mundo virtual, onde o ser sexy é a verdade, e a beleza se torna pornográfica (p. 91), dessa forma, tem-se um teatro pornográfico onde emoções são essencialmente mais fugazes do que sentimentos (p. 94). O teatro erótico é o lugar no qual é possivel a sedução, a fantasia pelo outro (p. 95). A beleza, é algo sempre a ser lembrado, deixando reminiscências, como a experiência proustiana da Madeleine mergulhada no chá (p. 103), sendo essa experiência privada do consumo, já que é apreendida pelo ser, pelo espírito, além de ser algo passado. Ao evocar a obra do escritor francês Marcel Proust (Em busca 
A noção de beleza na sociedade dos likes. imaginação, fantasia e consumo nas redes sociais digitais | Julio Marinho Ferreira

do tempo perdido), na qual as sensações do belo são a todo momento descritas, Han procurou fazer uma analogia ao gosto, ou ao sentimento que o belo causaria ao ser provado (sentido) pelo narrador. Dessa forma, o belo é sempre um produto a ser consumido pela novidade, e não pelo ter-sido (p. 103).

O belo deve ser algo demorado, e não efêmero, como na "internet das coisas", trazendo novamente o exemplo do on-line. Com isso, esse belo não produz narrativas, apenas enumera as ações, trazendo o sentimento do instantâneo, anulando a beleza poética, como a evocação de Proust sugere, "a beleza é vacilante, atrasada. O belo não é um brilho momentâneo, mas uma fosforescência quieta “ (p. 107). Nas palavras de Han, o filosofo existencialista alemão Martin Heidegger percebia o belo como um fenômeno da verdade, que escapava ao estético, e não apenas, já que a beleza também deixaria vestígios que não a aproximam da verdade. A beleza é dual, verdadeira e falsa, ao mesmo tempo, e o verdadeiro, como nos likes das redes sociais, produz um tempo sem erros, um tempo sem beleza (p. 111). A criação desse belo, ou de uma beleza, para Han, deve ser entendida distanciada da estética e experimentada a partir da relação pessoal que cada um tem com a verdade ou o verdadeiro em si.

Através de uma verdade pessoal, que seja próxima do belo e distanciada do simples consumo da beleza (pornográfica), notam-se as marcas de uma sociedade que prima pelo afastamento constante das relações sociais para as interfaces do mundo digital, aliadas às ideologias e às ferramentas neoliberais que permeiam as relações humanas contemporâneas. Dessa forma, essa breve obra de Han indica uma questão acerca de nossas vidas no universo do digital, onde as relações sociais parecem estar mediadas pelo consumo de imagem, que longe de uma inclusão apontaria para uma exclusão, já que o belo parece ser o objeto mais buscado e acessivel a poucos. Distanciada de um pessimismo, ou de um determinismo, "A salvação do belo" é um ensaio reflexivo sobre a noção de beleza na sociedade de consumo, além das possibilidades e dos usos desse belo pelas ferramentas tecnológicas do digital e do virtual. Dessa forma, o filosofo sul-coreano nos coloca frente à 
A noção de beleza na sociedade dos likes. imaginação, fantasia e consumo nas redes sociais digitais | Julio Marinho Ferreira

questão: o que seria o belo atualmente e como salvá-lo da enxurrada do consumo de uma sociedade neoliberal? 